\title{
Indirect Impact of Segregation Wall on the Investment in Renewable Energy in Palestine
}

\author{
By Husain Alsamamra ${ }^{1,3}$, Jawad Shoqeir ${ }^{2}$, Feras Zeade ${ }^{3}$
}

\begin{abstract}
Segregation wall played a pivotal role in making the renewable energy sector in Palestine insecure. This study assesses the direct and indirect effects of the Segregation Wall on investment in renewable energy in Palestine. Elucidate the possibility of confronting the policy of imposing unilateral sovereignty and clarifying the depth of the Palestinian-Israeli conflict over energy sector and renewable energy sector by separating residential complexes, which exacerbated the economic problems in various governorates. The study also showed that the Palestinians are highly dependent on the Israeli occupation in the energy sector, which makes the idea of dependence of the Israeli occupation economy. The historical approach has been used to follow up the Israeli occupation policy in the energy sector, in addition to using the descriptive approach and analyzing the investment policy in renewable energy sector. The construction of $771 \mathrm{~km}$ wall forced more than $41 \%$ of the Palestinians to abandon the lands that were confiscated from the lands close to the segregation wall, the wall confiscated many mountainous areas in West Bank that could be used to operate wind turbines. In addition to that $47.6 \%$ of Palestinian families lost their local source of income due to the construction of the segregation Wall, and the occupation authorities have demolished and closed many economic establishments near the segregation wall. The study recommended the importance of developing strategic plans by governmental and non-governmental agencies to promote investment in renewable energy, as the wall caused the demolition and closure of many economic institutions, which contributed to an increase in the poverty rate, which made it difficult to invest in renewable energy.
\end{abstract}

Keywords: Segregation Wall, Renewable Energy, Palestine, Investment

\section{Introduction}

The energy sector is Palestine suffers from the implications of the Israeli occupation. Which is responsible for the severe impacts on all life aspects in Palestine (Omar and Mahmoud, 2018). Gaza Strip and the West Bank are separated from each other. Gaza Strip is under siege since 2007, Israel applies strict bars on energy supplies to Gaza Strip. West Bank is divided into three administrative regions A, B \& C. According to the Palestinian Central Bureau of Statistics in 2018, Palestine consumed about 5,576 Giga watt hour of electricity, and about 931 tons of oil equivalent of Oil derivatives and 169 tons of oil equivalent of energy from renewable energy (Rabi and Ghanem, 2016). However, Palestine has high potentials of solar radiation with high sunshine hours throughout the year. The yearly average daily solar radiation on horizontal surfaces is about $5.6 \mathrm{kWh} / \mathrm{m}^{2}$,

| ${ }^{1}$ Al-Quds University, Department of Physics, Jerusalem, PO Box 89, Abu-Dies, Palestine; Corresponding Author

${ }^{2} \mathrm{Al}-\mathrm{Quds}$ University, Department of Earth and Environmental sciences, Jerusalem, PO Box 89, Abu-Dies, Palestine

${ }^{3}$ Renewable energy and sustainability, Joint master program between Al-Quds University and Palestine Polytechnic University 
while the total annual sunshine hours are about 3000 hours (Ghattas et al. 2016). These values are relatively high and receptive to the use of solar energy for solar water heating, photovoltaic applications, or other applications. (Hamed et al. 2012).

Since Palestine is an occupied country, there is no possible free electricity trading with neighboring countries (PEA, 2012). Thus, dealing with the unfair opposed prices of electricity is a daily fact that hinders the prosperity and growth of this sector, and many other sectors.

Investing in renewable energy is directly linked to a number of factors, including economic and political factors, which led to political pressure against the Palestinians (Al-Hadath Magazine, 2017). The construction of the segregation wall in 2002 is an extension of the theft of Palestinian land since the beginning of 1948 under the pretext of protecting Israeli citizens, which led to the confiscation of large areas of Palestinian land, which resulted in a difficult situation for investment in renewable energy (Ghattas et al. 2016), as well as obstructing the import of equipment and technology for alternative energy applications, in an effort to continue the Palestinian energy resources controlled by the occupation and thus limit the Palestinian independence of the energy sector (Alsamamra and Shoqier, 2021) The direct aim of the segregation wall is to eliminate any idea of a project that could be independent from Israel by the Palestinians, because Israeli energy companies control the energy sector completely (Farinacci, 2017). The lack of Palestinian citizens' financial income has complicated even more as many areas have been isolated and gates have been set up to prevent freedom of movement making it difficult to save money for renewable energy investments (PEC, 2007). According to the Palestinian Statistics Center, more than $46 \%$ of the Palestinian land were confiscated, which led to the destruction of the crisis infrastructure to renewable energy projects. The Israeli occupation forces have halted renewable energy projects near the segregation wall, such as the village of Jeb El Deeb in Bethlehem (Energy Research Center, 2020), a solar energy equipment was confiscated.

As explained by Dweik (2018), the construction of the segregation wall represents one of the chapters of racism and Israeli thought, which aimed to destroy all the foundations of the Palestinian state, and contradicts all international treaties and covenants; including the decisions of the International Court of Justice against the legitimacy of the segregation wall. As a reason for isolating Palestinian communities from their lands, and isolating the Palestinian market from foreign markets. Thus, the inability to separate from the Israeli market, besides the segregation wall that is the main destroyable practice ever implemented, for which it confiscated high rate of the Palestinian lands. (Ismail et al., 2013) A large percentage of lands has been stolen, which affects the areas that can be used to establish renewable energy projects since it needs large areas, in addition to the risks associated with any investment attempt in economic fields in light of the unstable economic and political situation. This study examined the economic challenges resulting from the construction of the wall in addition to the Israeli occupation procedures in the process of destroying the Palestinian economy as well as the process of destroying the infrastructure needed to build energy projects.

\section{Literature Review}

Palestine has a huge need for each kind of energy to grow the economic and human development due to it's one of the developing nations. According to the Palestinian 
Central Bureau of Statistics, the total electrical energy consumption in Palestine in 2019 was reported to be 5,929.5 GWh. This quantity is almost entirely imported from outside sources, mainly, 93.4\% from the Israel Electric Corporation, 4.4\% from Gaza power plant, 1.6\% from Jordan and 0.6\% from Egypt (Milhem, 2020, Alsamamra and Shoqier, 2020a). Electricity generation through thermal power plants also needs sources imported from Israel with high costs such as natural gas or petroleum fuel, and in another hand, thermal power plants require large spaces of land far away from the population and city centers which are hard to achieve in the current conditions. Local power generation serves a strategic Palestinian choice to diminish the dependence of the electricity sector from Israel and likewise to decrease the costs of electricity which are expensive as compared to costs in the nearby countries (Ibrik, and Hashaika, 2019).

In the Palestinian Territories, natural resources such as solar energy, wind energy, and biomass are available, with promising potential at different locations. Unfortunately, this availability is not reflected in its contribution to energy balance (Sustainable Development Administration, 2007). The Palestinian Authority's concerns to invest in these resources to improve the reliability of energy supplies and mitigate environmental impacts, taking into account economic factors and energy security issues. This would lead to a more independent Palestinian energy system (Ismail et al., 2013). The Israeli occupation aims to prevent the establishment of the state of Palestine and impose unilateral solutions through total control of the energy sector (Jallad, 2004). Through the research carried out by the Palestinian Environmental Organizations Networks, (2003), it was made clear that Israel plans to isolate Palestinian communities and divide them into geographically separated societies, which led to the direct destruction of the Palestinian economy.

Despite financial and technical issues, the availability of natural resources and the required technology encourages the implementation of such projects (Melhem, 2020). Different authorities and non-government organizations in the Palestinian Territories work in the energy and environment sectors. These include the Palestinian Energy and Environmental Research center, Palestinian Energy authority, different university research centers, and others (Hamed et al., 2012). However, the results of the World Bank Group Final Report (2016) indicated that the estimated contribution of renewable energy generation to total energy consumption is about $6.3 \%$ of the required energy demand in the Palestinian territories, which is an insufficient percentage of the total energy consumption. The Palestinian Energy Authority aims to improve using renewable energy to accomplish 10\% of the total demand for electric energy, in other words aims to produce $130 \mathrm{MW}$ of electricity by the year 2020 (Alsamamra and shoqier, 2020b). However, only 90 MW of solar PV are estimated to have been installed to date, generating less than $3 \%$ of the electricity demand ( Milhem, 2020).

According to Milhem (2020) the Palestinian Energy and Natural Resources Authority adopted a new national action plan (2020-2030) that aims to accelerate the deployment of renewable energy technologies and to improve energy security by diversifying its sources of electricity and reducing the country's dependence on imported power supply; increasing the use of clean energy. This action plan proposes the following RE targets:

- 2030 target - scenario A: 300 MW, including only areas A and B.

- 2030 target - scenario B: $500 \mathrm{MW}$, including areas A, B, and C.

Eighty percent of the 2030 targets will be achieved with solar PV, 10 percent with wind 
energy, and 10 percent with biogas/biomass.

However, For a $1 \mathrm{MWp}$ on-ground structured PV power plant, based on local market price ratings, the capital expenditure amounts to 0.9 US $\$$ to 1.1 million, including modules, inverters, electrical cabling, mounting structure, civil work, installation, and engineering cost. The operating expenditure is estimated at 32,000 US\$, including operation and maintenance with five cleaning cycles, spare parts, inverter maintenance, and power lines, in addition to insurance and administrative costs Milhem, 2020).

Moreover, different challenges are facing the implementation of PV projects, both on small or large scales. These challenges may limit the spread of this technology. Any solar energy project generally requires high financing and technological requirements; the availability of highly qualified persons for design and installation; the availability of space, and infrastructure for storage system (Makhou et. al., 2005). Moreover, standby energy source if required, and connection to the grid regarding the solar energy. However, obtaining finance for small-scale standalone PV projects is usually easier (Makhou et. al., 2005). Success in these projects in the pilot-scale will lead to more investment in largerscale projects, so the plan for investment in PV applications should begin from small projects. (Solangi et al., 2011).

A descriptive study conducted by (Hamed et al., 2012) stated that the segregation wall in Palestine, led to the confiscation of large areas of Palestinian lands. Where renewable energy use has been mitigated, and unable to be implemented. Accordingly, it is obvious that the renewable energy resources are useful and beneficial for the economic development of Palestine (Mujali \& Suqur, 2003). Ibhis \& Ayed (2013) pronounced that the segregation wall has destroyed the trends of Palestinian communities and leaders toward investment in several elements of the economy, which the renewable energy resources are one of the most important elements. However, Al-Sharafi (2018) stated that the renewable energy investment leads to the dependency of the Palestinian economy, as worth mentioning that the Oslo agreement and its appendices forced the Palestinian economy to be dependent on the Israeli economy.

In other context, the renewable energy resources in Palestine are highly exist, in which the Palestinian lands are rich in sun, wind, and running water. However, Israeli practices led to restricting the Palestinian government and private sector toward investing in renewable energy (Economic and Social Commission for West Asia, 2004). However, the segregation wall is one the most important and destroy practice that has been implemented by Israelis, which restricted all types of efforts toward investing in renewable energy. In a study prepared by the Ministry of Planning and International Cooperation (2004), to lay down a general framework for Palestinian social and economic development under the current circumstances. It focused on the importance of linking relief to economic development, and the need to use available resources more effectively. In addition to reconnect the Palestinian economy with the Arab economy, which enhances the resilience of the people. Furthermore, World Bank study (2004) showed that the economic conditions of the Palestinians are approaching a disaster. The study concluded that the Palestinians are facing the worst economic recession in their contemporary history. The main reason for this stems from the Israeli restrictions imposed by the Israeli occupation on the movement of people, products, and goods. The study also showed that there is a sharp deterioration in the gross domestic product, a decline in income, and an increase in the unemployment and poverty rate. 


\section{Electricity Status in Palestine}

Energy safety is one of the predominant challenges that Palestine faces nowadays; in which a necessary obstacle towards realizing sustainable political and financial independence (Sayegh, 2007). However, Palestine imports all oil derivatives \& energy from Israeli occupation, and as per the Oslo agreement, all land crossings and borders are under the control of the Israeli occupation. As shown in figures 1 and 2 most electrical consummation came from Israeli occupation. (Palestinian energy and natural resources authority, 2018).

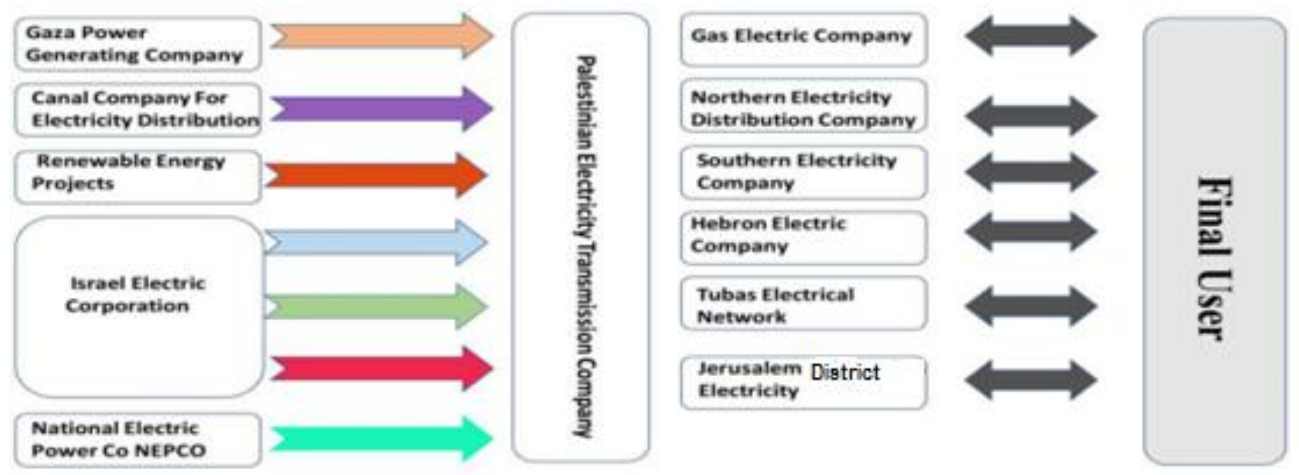

Figure 1: Energy distribution to the Palestinians

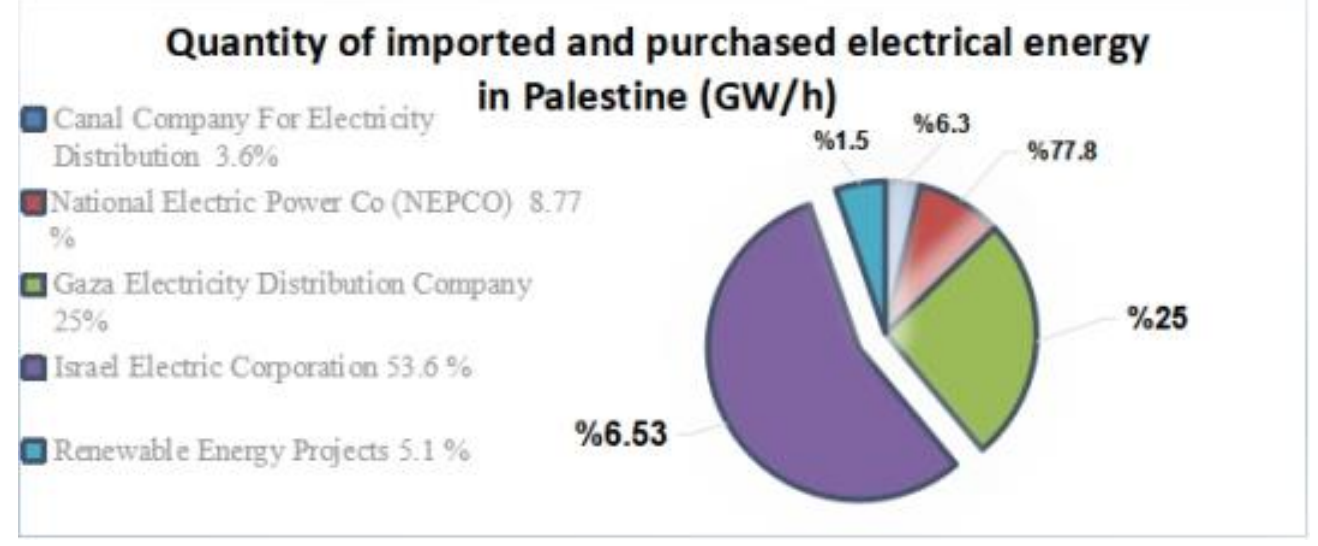

Figure 2: Quantity of imported and purchased electrical energy in Palestine (GW/b)

In the same context, the field of energy in Palestine is similar to what happened in many fields that have accumulated due to the Israeli occupation since 1948 (Rabi \& Ghanem, 2016). A study of the Palestinian Coordination Agency for Statistics (2015), showed that the Israeli occupation imposed many restrictions on improving the energy solar energy field. Which led to the absence of improvement in the efficiency scale in light of the high consumption. On the other hand, electrical energy is highly costly in Palestine rather than the Middle East and North Africa, and represent a massive percentage of family running 
costs. Accordingly, energy remains the biggest obstacle in front of the Palestinian government, due to the Israeli Electricity Authority's control over the energy use in Palestine through direct alignment with neighborhood clusters. (Arrangement and Events Management Service, 2012)

Nevertheless, the occupation's strategy of ignoring its duties towards the Palestinian Authority's area is the main reason for widening the dispute between the Palestinians and the Israeli occupation (Judeh. et. al, 2017). In addition, every practice is forced to be implemented in the Palestinian land (World Bank Group, 2014). Moreover, in the absence of a binding electricity agreement for the Israeli occupation, the Israeli Electricity Company illegally controls the electricity sector. (Al-Haq, 2015)

The sustainability of the Palestinian Authority and its ability to ensure the provision of basic services, including its ability to provide electricity, has become impossible. Therefore, we must move towards an alternative.

\section{Renewable energy in Palestine versus Segregation Wall}

Solar energy is still the most practical source of green energy in the Palestinian areas. Which the amount of solar energy from the total renewable energy production in Palestine, is estimated at 40\% (Regional Center of Renewable Energy and Energy Efficiency, 2015). On the contrary, solar energy in Palestine faces financial constraints and determinants of human efficiencies, in addition to the unstable economic situation, to the difficulty of investing in solar energy (Yaseen, 2007, Al-Rimawi, 2015). After 1995, the signing of the Oslo Agreement between the Israeli occupation and the Palestinians, the Israeli occupation divided the West Bank into three areas, as follows: (Khalidi \& TaghdisiRad, 2009)

O Areas (A) constitute 3\% of the West Bank and are administratively subject to the Palestinian Authority.

O Areas (B) constitute $21 \%$ of the West Bank, which is partially subject to the Palestinian Authority in the education and health sectors.

O Areas (C) constitute $60 \%$ of the West Bank, which is under the control of the Israeli occupation.

In the same context, Humaid (2013) explained that in light of the division of the Palestinian territories under the Oslo Agreement, Palestinian sovereignty over the land became impossible. Which made it difficult to invest in renewable energy due to the destruction that occurred to the Palestinian economy (Abu Aisha, 2020). In addition to the process of building the wall, which increased the extent of the devastation in the sector of investment in renewable energy linked to the Palestinian economy. (Al-Omari., 2019)

As shown in figure 3 the segregation wall is about $770 \mathrm{~km}$ long (Institute for Palestine Studies 2004) and extends along the eastern mountains in a way that enables Israel to control the Jordanian valleys and extends along with Palestinian land. The length of the barrier is due to many upcoming turns due to the interactions between the Palestinian territories and settlements (Palestinian Center for Human Rights, 2004). The Segregation wall confiscated many mountainous areas in the West Bank that could be used to operate wind turbines (Zughayer, 2015). The highest wind speed was observed in 2005 in Bethlehem and Hebron cities, with average values of $13.4,12.7$, and $12.2 \mathrm{~km} /$ hour 
respectively. These are equivalent to $3.72,3.53$, and $3.39 \mathrm{~m} / \mathrm{s}$ respectively (Salem et al. 2007).

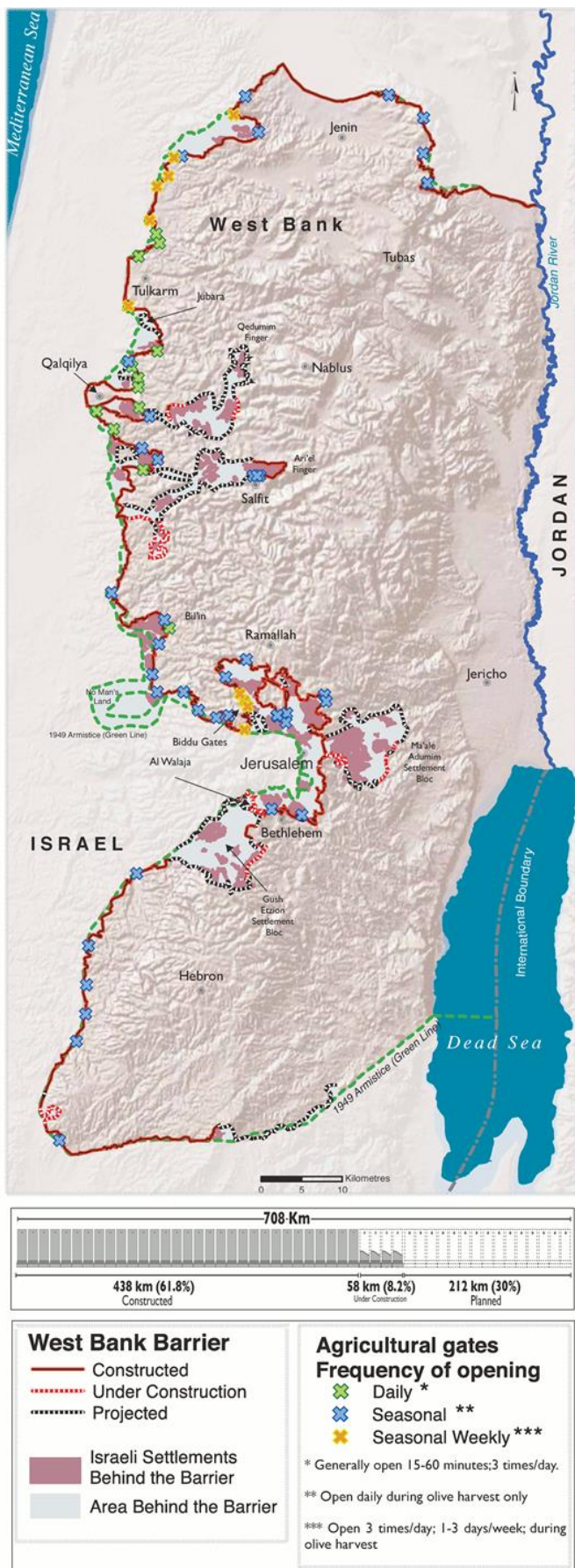

Figure 3: Segregation wall route in the West Bank, Palestine (Central Statistical Organization, 2004) 
According to these data, it is clear that the possibility of establishing wind energy projects is possible, but according to the study (Karzam, 2009), the segregation wall destroyed many roads and infrastructure that directly affected the possibility of investing in renewable energy. By tracking the map of the wall in the West Bank, the impact of the wall on governorates was significant, and the high areas were a target of confiscation, which led to the loss of some heights that could be used in wind energy. (The Applied Research Institute, 2015)

However, the governorates were directly affected by the economic sector, due to the extension of the segregation wall deep into and around residential communities (Oberholzer, 2015). The segregation wall also caused the separation of the families geographically and economically, which led to the loss of sources of income. Studies indicate that $47.6 \%$ of Palestinian families lost their local source of income due to the construction of the separation wall (Yaqin, 2002). In addition, the occupation authorities have demolished and closed many economic establishments near the segregation wall (Palestinian Central Statistics, 2008). This caused the inability to exploit or access those establishments. In addition to the destruction of many roads and infrastructure, which are necessary to establish renewable energy projects (The Wall and Settlement Resistance Commission, 2020). All these reasons have led to the difficulty of investing in renewable energy, in the areas close to the segregation wall due to the high cost of the crisis to establish renewable energy projects.

Studies have shown that $41 \%$ of the Palestinians abandoned the lands that were confiscated from the lands close to the segregation wall (Yaqen, 2002). Due to the difficulty of accessing them or because of the Israeli occupation measures aimed at removing the Palestinian community from its land (Al Badel center and displacement control center, 2006). Thus, the Palestinians are refraining from investing in renewable energy in areas close to the wall, for the reason of Israeli occupation measures threats, which could lead to the destruction of any project (Abu Atta, 2018). Also, the segregation wall implemented a policy of displacement of the Palestinian population, whether internal or external migration (Abu Al-Rub, 2005). Moreover, as shown in table 1, studies showed the percentage of displaced families close to the wall:

Table 1: Displacement of the Palestinian peoples according to each city.

\begin{tabular}{l|c} 
Governorate & Displaced Persons \% \\
\hline Jerusalem & $30 \%$ \\
Bethlehem & $46.20 \%$ \\
Qalqilya & $29.60 \%$ \\
Hebron & $29.10 \%$ \\
Nablus & $27.70 \%$ \\
Jenin & $19 \%$ \\
Ramallah & $11.90 \%$ \\
Tulkarm & $9.50 \%$ \\
Salfit & $7.30 \%$
\end{tabular}

Table 1 shows that more than $69.1 \%$ of the Palestinians, who hold an Israeli identity were forced to change their place of residence to the Israeli occupation lands. Thus, transferring the capital that could be used in investing in renewable energy (BADIL, 2009). 
The segregation wall cuts off many Palestinian communities and villages from neighboring towns and cities. Individuals living in segregation zones or newly created ethnic Palestinian ghettos are separated from friends and relations living in nearby villages. Residents of the ghettos are required to obtain permits from Israeli occupation authorities simply to access their homes. Non-residents are restricted from entering these areas. Additional Palestinian communities have been isolated from their agricultural lands which lie on the opposite side of the wall. As a result, the construction of the segregation wall will significantly impair the ability of many Palestinian the families to earn their living.

The segregation wall will also affect the educational system in the West Bank; according to the Palestinian Central Bureau of Statistic $26 \%$ of Palestinian students lose their rights and access to proper education and $81 \%$ of Palestinians in regions affected by the wall will be forced to find alternative routes to their schools and universities as a result of the wall. The political strategies of the Palestinian leadership must be built toward resisting the wall, considering the areas adjacent to the wall, as a priority in infrastructure projects. In addition to awareness programs through government centers in Palestinian communities near the wall. (Jumaa, 2011)

\section{Conclusions and Recommendations}

The conflict between Israelis and Palestinians is one of the most complex and intractable conflicts of our time and has drawn enormous attention from scholars and policymakers worldwide. The multifaceted system of Israeli control over Palestinian movement, known as the closure regime, is but one of the dimensions of the conflict that has been extensively documented. Countless studies have shown that the movement and access restrictions imposed by Israeli authorities are detrimental to the Palestinian economy and have been impeding economic growth, private-sector growth, and long-term competitiveness. Since the start of its construction in 2002, the West Bank wall has become a stark and unavoidable reminder of the external closure regime that Israel imposes on Palestinians. The construction of the wall has a significant, negative impact on labour force participation rates, probably as a result of reduced access for Palestinians to their workplaces on either side of the wall. Indeed, controlling for the gate and permit regime, the number of Palestinian fatalities, the availability of credit, as well as Israeli working permits allocated to Palestinians could provide the basis for a more in-depth estimation analysis. However, the most severe impact of the segregation wall is the isolation of huge parts of Palestinian land, these areas comprise almost $50 \%$ of Palestinian land in the occupied Palestinian territories.

Moreover, the construction of the wall restricting Palestinian livelihoods, which involves huge financial losses in the investment through considerable land confiscations and the destruction of many economic assets such as solar energy projects, agriculture and water resources. In addition, occupation authority obstructing the import of equipment and technology for alternative energy applications and thus displaced the investors from carrying out any investment plans in renewable energy in the lands adjacent to the wall.

Palestine is completely dependent on the Israeli occupation, to supply its energy and electricity needs. However, Palestine receives a huge amount of solar radiation and the prices of oil and oil derivatives are relatively high compared to other Arab and international 
countries. The presence of renewable energy to promote and develop sustainable energy for the Palestinians is an important issue. Focusing on reducing dependence on energy imports from the Israeli occupation and increasing the use of renewable energy sources available in Palestine is one of the ways to enhance steadfastness and confront the Israeli occupation.

Renewable energy represents one of the main sources outside of conventional energy, as well as being clean energy that does not pollute the environment, this makes it extremely important in achieving sustainable development. In addition to increase the rate of cultural and intellectual awareness among the people of the country and the benefits of investment. Establishing small projects, especially in remote areas, to reduce dependence on fossil fuels and support resilience in their areas.

Segregation Wall has many effects on Palestinians including reduced freedoms, loss of land, increased difficulty in accessing medical and educational services, restricted access to water sources, and economic effects. However, this work recommends that, all areas close to the wall be considered first-class development zones in economic plans and policies; setting strategic plans for the renewable energy sector and giving them priority to reconstruction and development; the necessity of the Palestinian official authorities to act to develop the infrastructure and provide all services through the development of government centers, in addition to that, work on the regional and international cooperation through governmental and non-governmental institutions to exchange ideas and experiences. Also, it is necessary to stop or limit the migration of the Palestinian population from the areas adjacent to the wall and to strengthen their steadfastness by providing job opportunities and providing private projects. Future plans must also be introduced, government plans by replacing the horizontal building that consumes large areas with vertical construction as a way to compensate for the lost space. Highlighting the risks arising from the establishment of the segregation wall in international and Arab forums and focusing on them on the Palestinian media map, in order to left vast spaces to educate the Arab public and the Palestinian dangers to the Palestinian cause.

\section{References}

Abu Aisha, N. (2020). 27 years after "Oslo": What is left of the agreement? (report): https://www.aa.com.tr/ar/ Abu Al-Rub, Mahmoud. (2005). The direct economic and social effects of the segregation wall on the Palestinian people 2005, Open Al-Quds Journal for Research and Studies (5).

Abu Atta, A. (2018). The Zionist separation wall and its repercussions on the Palestinians: https://www.almayadeen.net/butterfly-effect/852063

Alsamamra, H. and Shoqier, J. (2021). Solar Photovoltaic Systems on Public Schools Buildings: A Case Study in Palestine. American Journal of Electrical Power and Energy Systems, 10(1), 1-5.

Alsamamra, H. and Shoqier, J. (2020). Assessment of Wind Power Potential at Eastern-Jerusalem, Palestine. Open Journal of Energy Efficiency, 9, 131-149.

Badel center and displacement control center. (2006). Forced displacement caused by the wall, a preliminary study on the forced displacement caused by the wall and the associated system.

Al-Hadath Magazine. (2017). Palestinian and Israeli solar energy struggle. https://www.alhadath.ps/article/13096.

Al-Haq. (2015). Exploiting and preventing the developments of oil and gas in occupied Palestinian territory: https://www.alhaq.org/cached_uploads/download/alhaq_files/publications/Annexing.Energy.pdf

Al-Omari, G. (2019). The Distorted Legacy of the Oslo Accords, Washington institute: https://www.washingtoninstitute.org/ar/policy-analysis/view/oslos-mangled-legacy 
Al-Rimawi, H. (2015). Birzeit University. https://interactive.aljazeera.com/aja/palestineremix/areac.html\#/2

Al-Sharafi, Rami. (2018). Preparing public reporting and strategic thinking, Masarat Center , https://www.masarat.ps/article/4808/

Dweik, Mosa. (2018). The Deadly Separation Wall and Its Negative Economic Effects on the Palestinian People 2014, Open Al-Quds Journal for Research and Studies (37).

Economic and Social Commission for West Asia. (2004). Report of the 28 session, Appendix No. 21 , beirut - lebanon

Energy Research Centre. (2020). Renewable Energy in Palestine. An-Najah National University, Nablus, P.O. Box 7, West Bank, Palestine.

Farinacci, Elisa. (2017). The Israeli-Palestinian Separation Wall and the Assemblage Theory: The Case of the Weekly Rosary at the Icon of Our Lady of the Wall. Journal of Ethnology and Folkloristics. DOI: 11. 10.1515/jef-2017-0006.

Ghattas, R., Rishmawi, K., Isaac, J., (2016). Opportunities and Challenges of Palestinian Development Actions in Area C. Applied Research Institute- ARIJ. Bethlehem, Palestine.

Hamed TA, Flamm H, Azraq M. (2012). Renewable energy in the Palestinian territories: opportunities and challenges. Renewable and Sustainable Energy Reviews. 6 (16):1082-1092.

Humaid, B. (2013). Under the control of the Israeli occupation on energy production in Palestine, "Energy independence first": https://ps.boell.org/ar/2013/01/27/fy-zl-sytr-lhtll-lsryyly-l-ntj-ltq-fy-flstynstqll-ltq-wl

Ibhis, H. \& Ayed, K. (2013). Separation Wall in West Bank. Al-Zaytouna Centre for Studies and Consultations , beirut - lebanon copy number 1 .

Ibrik, I. and Hashaika, F. (2019). Techno-Economic Impact of Grid-Connected Rooftop Solar Photovoltaic System for Schools in Palestine: A Case Study of Three Schools, International Journal of Energy Economics and Policy, 8, 291-300.

Ismail, M.S., Moghavvemi, M., Mahlia, T. (2013). Energy trends in Palestinian territories of West Bank and Gaza Strip: Possibilities for reducing the reliance on external energy sources. Renewable and Sustainable Energy Reviews. 28, 117-129.

Jallad, Emad. (2004). Ministry of National Economy, the impact of building the first stage of the Segregation Wall On the commercial and industrial sectors.

Judeh, T. \& Ozerol, G. (2017). Assessment of water governance in the West Bank, Palestine , Al-Najah National

University: https://www.researchgate.net/profile/Guel_Ozerol/publication/315906202_Assessment_of_wat er_governance_in_the_West_Bank_Palestine/links/5a5fbcb4aca272735244df9a/Assessment-ofwater-governance-in-the-West-Bank-Palestine.pdf

Jumaa, J. (2011). Is an activist in the popular campaign to resist the wall and settlement - the West Bank: http://palestine.assafir.com/Article.aspx?ArticleID=1824

Karzam, G. (2009). Racial walls and colonial motives to destroy Palestinian ecosystems: https://www.maanctr.org/magazine/Archive/Issue14/main_topic/topic1.htm

Khalidi, Raja J. and Taghdisi-Rad, Sahar. (2009) mpra.ub.unimuenchen.de/21808/1/MPRA_paper_21808.pdf

Makhou, B. Abu Kaoud, H. Nazzal, M. (2005). Methods for improving the profitability of those affected by the separation wall, The Palestinian Economic Policy Research Institute (MAS).

Melhem, Zafer. (2020). Al-Hadath Magazine interview, Palestinian strategy in the field of energy .

Milhem, Z. (2020). Paving the Way for a Renewable Energy Future in Palestine. http://www.penra.pna.ps/ar/Uploads/Files/Paving $\% 20$ the $\% 20$ Way $\% 20$ for $\% 20 \mathrm{a} \% 20$ Renewable $\% 20$ Energy $\% 20$ Future $\% 20$ in $\% 20$ Palestine.pdf

Mujali, nader \& Emad Suqur. (2003). Separation plan between Palestine and Israel Forum for Political and Economic Research, Ramallah.

Oberholzer, F. (2015). The Impact of the West Bank Wall on the Palestinian Labour Market. The Impact of the West Bank Wall on the Palestinian Labour Market (openedition.org)

Omar, M and Mahmoud, M. Economic evaluation of residential grid connected PV Systems based on NetMetering and Feed-in- Tariff schemes in Palestine ",International Journal of Renewable Energy Research, 8(4), 2018. 
Palestinian Central Bureau of Statistics (PCBS). Press Report: Preliminary Estimates of Quarterly National Accounts' (First Quarter 2015) 7.

Palestinian Central Bureau of Statistics (PCBS). (2018). Publications energy, household energy survey: main results. http://www.pcbs.gov.ps/pcbs_2018/Publications.aspx

Palestinian Central Statistics Authority. (2015). The Applied Research Institute - Jerusalem (ARIJ) Annual Report 2004.

Palestinian Central Statistics. (2008). The impact of the Annexation and Expansion Wall on the reality and economic situation of the Palestinian communities located in the Wall from their lands.

Palestinian Energy Authority. (2012).The Overall strategy for Renewable Energy in Palestine, Ramallah Palestine

Palestinian Energy and Environment Research Center (PEC) master plan for RE in Palestine, 2007-2012, Technical Department.

Palestinian Environmental Organizations Networks (2003), The Segregation Wall in Palestine , Jerusalem

Palestinian Meteorological Station. (2010). Monthly climate averages. https://web.archive.org/web/20100704174632/http://www.pmd.ps/ar/climateaverage.htmt

Publications of the Applied Research Institute - Jerusalem (ARIJ). (2015). Status of the Environment in the State of Palestine.

Rabi, A., and Ghanem, I. (2016). Pre master plan solar energy production in Palestine: Opportunities and challenges. Palestinian Environmental NGOs Network - Friends of

Regional center of renewable energy and energy efficiency (RCREEE). (2015). Arab future energy index afex renewable energy, cairo, p35.)

Salem, H. S. et al. (2007). Status of the Environment in the Occupied Palestinian Territory. Applied Research Institute-Jerusalem

(ARIJ). https://www.researchgate.net/publication/301608421_Status_of_the_Environment_in_the_Occ upied_Palestinian_Territory_Edited_by_Prof_Hilmi_S_Salem_Jane_Hila 1_and_Roubina_Ghattas

Sayegh, R. (2007). The Palestinians From Peasants to Revolutionaries.

Solangi, K., Islam, M., Saidur, R., Rahim, N., Fayaz, H. (2011). A review on global solar energy policy, Renewable and Sustainable Energy Reviews, 15, (4), 149-216. https://doi.org/10.1016/j.rser.2011.01.007.

Wall Information Center. (2012). http://pnn.ps/news/528485

World Bank Group (2016), West Bank \& Gaza Energy Efficiency Action Plan, Final Report, June 2016

World Bank Group. (2014). Assessment and Action Plan to Improve Payment for Electricity Services in the Palestinian Territories: Study on Electricity Sector Contribution to Net Lending, Executive Summary' (2014) 15.

Yaqin, S. (2002). A study in demographic politics and ethnic cleansing (2002-2014) The Israeli Separation Wall.

Yaseen, B. (2007). Energy Authority Technical Department Director (PEC), Palestine.

Zughayer, R. (2015). The Separation Wall and its impact on the social, environmental and water fabric in the Ar Ram and Dahiyeh areas, page 133-135 